\title{
Intestinal lipomatosis in a 10-year-old girl
}

\author{
A. Bodas $\cdot$ F. Rivilla $\cdot$ C. Maluenda
}

Received: 5 March 2007 / Accepted: 22 May 2007 /Published online: 14 June 2007

(C) Springer-Verlag 2007

\section{Introduction}

Lipomatosis involvement of the gastrointestinal tract is a rare disorder, for which few cases have been reported in medical literature [1, 2]. Benign tumors of the small bowel are relatively rare; lipomas are among the most common ones, with an incidence in autopsy ranging from $0.04 \%$ to $4.5 \%$ [4]. We report a 10 -year-old girl with lipomatosis involving small and large bowel.

\section{Case report}

A 10-year-old girl was referred with a history of recurrent abdominal pain for the last 12 months. Pain was severe and gradually increasing in the right upper abdominal quadrant. She had no symptoms or signs of intestinal obstruction. No relevant past medical or family history was reported. Results of a haematological examination, liver function test, urine analysis and stool occult blood test were all within normal ranges. Abdominal ultrasonography revealed a "target" mass $(10 \times 6 \mathrm{~cm})$ in the right upper quadrant. Abdominal computed tomography demonstrated an $11.4 \times$ $1.4 \times 5.2 \mathrm{~cm}$ mass in the right hypochondrium, with fat density. At laparotomy, a large lipoma $(10 \times 15 \mathrm{~cm})$ in the mesenteric area of the right colon was resected (Fig. 1). The cut section showed multiple submucous jejunal and ileal lipomas, sized from 2 to $8 \mathrm{~cm}$; ten of them were resected.

\footnotetext{
A. Bodas $(\bowtie) \cdot$ F. Rivilla $\cdot$ C. Maluenda Department of Pediatrics, Hospital Clínico San Carlos, 28040 Madrid, Spain

e-mail: andresbpinedo@yahoo.es
}

Microscopic examination of the specimen showed many small-to-large tumors, composed of mature adipose tissue and thin fibrous septa, in the submucosal and serosa, with preservation of muscularis propria. The postoperative period was uneventful and the patient was completely symptom free during 10 months of follow-up.

\section{Discussion}

The term lipomatosis has been used to describe the presence of numerous circumscribed lipomas in the intestine [3, 4]. Lipomatosis of the small bowel was first described by Hellstrom in 1906, and is uncommon [4]. Case reports of lipomas in isolated or scattered segments are most frequently encountered in the literature. The ileum

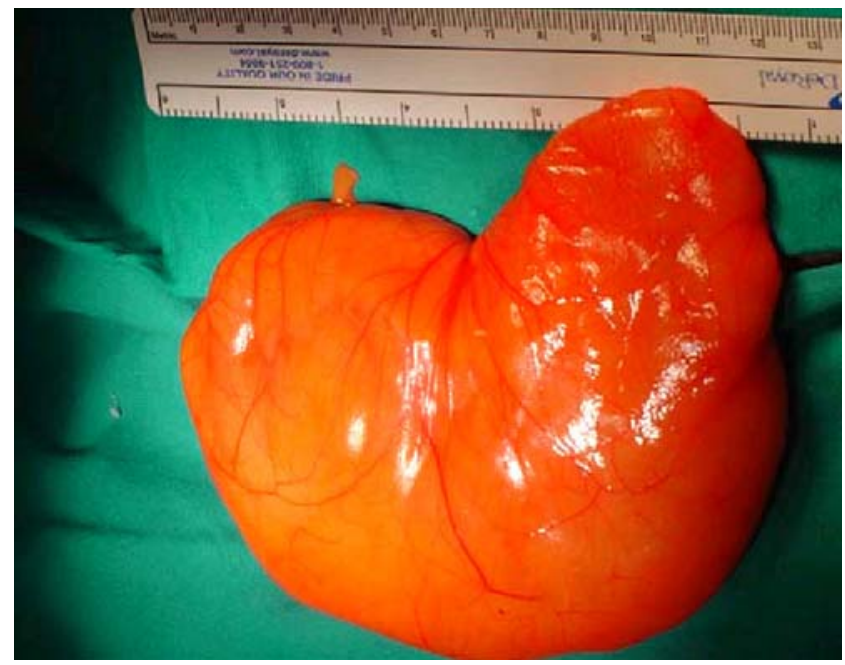

Fig. 1 Intestinal lipoma 
is the most commonly affected site [6]. There is no satisfactory explanation for the etiology of gastrointestinal lipomatosis [6]. No gender predilection is observed [5]. Intussusception or intestinal obstruction is a frequent clinical presentation. The most frequent presenting symptom is abdominal pain [3]. Simultaneous lipomatosis and diverticulosis has been documented [6]. Melena usually occurs from intussusception or ulceration of lipomas $[3,6]$. Some patients with lipomatosis have a familial history, suggesting an autosomal dominant inheritance [6]. Hypercholesterolemia has also been reported often [6], but this was not found in our patient. Lipomatosis usually occurs after the fourth decade of life. Yakabe et al. documented six cases and reviewed a total of 23 cases with an age distribution ranging from 20 to 88 years [6].

\section{References}

1. Devlies F, Hoe LV, Leemans A, Ponette E, Paepe ID (1997) Gastroduodenal lipomatosis. Eur Radiol 160:311-312

2. Duun S (1994) Lipomatosis of the small intestine. Eur J Surg 160:311-312

3. Shenoy R, Rodríguez G, Gopashetty M, Kannaiyan L, Rao S (2003) Segmental jejunal lipomatosis: a rare cause of intestinal obstruction. Yonsei Med J 44(2):359-361

4. Tani T, Hajime A, Hiroaki T, Masashi K (1998) Lipomatosis of the ileum with volvulus: report of a case. Jpn J Surg 28:640-642

5. Tatsuguchi B, Fukuda Y, Moriyama T, Yamanaka N (1999) Lipomatosis of the small intestine and colon associated with intussusception in the ileocecal region. Gastrointest Endosc 49:118-121

6. Yakabe S, Muranaka T, Sumii T, Takeshita M, Yamashita T, Tsuruta S, Saku M, Yoshida K (1998) Jejunal lipomatosis with diverticulosis: report of a case. Jpn J Surg 28:846-849 